\title{
Taking Race Live: Exploring experiences of race through interdisciplinary collaboration in higher education
}

\author{
Sonya Sharma*, Elena Catalano, Heidi Seetzen, Helen Julia Minors and \\ Sylvia Collins-Mayo - Kingston University, UK
}

\begin{abstract}
In this article we discuss an interdisciplinary and collaborative four-year project, Taking Race Live, that explored lived experiences of race among students enrolled at an ethnically diverse university in England. Utilizing qualitative methods to evaluate the project each year, we draw on students' voices to address their experiences of race, partnering with interdisciplinary peers and learning about each other. Framing the discussion are the concepts of 'liveness' and 'public sociology' proposed by sociologists to bring sociological knowledge alive. Attention is given to how this was done through engaging with the arts and embodied practices found within drama, dance and music.
\end{abstract}

Keywords: race; collaboration; interdisciplinary; sociology; student partnerships

\section{Introduction}

Research recently conducted by Crozier and colleagues (2016: 39) found that: 'In spite of the relative success of the Widening Participation policy and strategies to increase the numbers of students from Black and Minority Ethnic and White workingclass backgrounds going to university, universities in Britain continue to be White and middle-class-dominated institutions.' There is still significant underrepresentation of some student groups in selective institutions (McDuff et al., 2018: 79). For instance, 'Black, Pakistani and Bangladeshi groups are less likely than White students to be offered places for entrance into elite Russell Group universities' (BIS, 2013, cited in Bhopal, 2018: 91). Once they get to university, minority ethnic groups' first-degree attainment is less than their White peers (Richardson, 2018: 87). More so, racialized terms such as 'Black and minority ethnic' (BME) are problematic and can hide a range of social structures that intersect to create different experiences of access and equality (Crenshaw, 1989). Thus, uneven attainment in higher education is complex, and there are efforts to examine and understand how institutional contexts play a role (McDuff et al., 2018; Ross et al., 2018) with regard to academic cultures, curricula and hiring practices.

'University institutions have themselves proved remarkably resilient to change in terms of curriculum, culture and staffing, remaining for the most part "ivory towers"' (Alexander and Arday, 2015: 4). Attempts to shed light on the reluctance to attend to structures of race and ethnicity in these areas have been prominently noted by recent student campaigns and events, such as 'Why is my curriculum White?' and 
'Why isn't my professor Black?' (Hussain, 2015; Morgan, 2016). These have resulted in initiatives to address these challenges, such as: the Runnymede Academic and Emerging Scholars Forums (2013-14) that paid particular attention to the number of minority ethnic academics in higher education; Attainment, Curriculum and Employability; and Access and Widening Participation (Alexander and Arday, 2015: 4). Events have also been held by the University and College Union and National Union of Students to address race and racism in further and higher education. The Higher Education Race Action Group (2016) promoted the development of inclusive curricula across academic disciplines. The Equality Challenge Unit (2014) set out the Race Equality Charter to recognize these institutional issues, including the poor record of representation of minority ethnic staff in institutional and leadership positions in universities (ECU, 2016).

Further developments in government policy have led to the Teaching Excellence Framework (TEF), which aims to promote high-quality teaching, but its metrics and responses do little meaningful work to redress the balance of student diversity, nor do many of the initial submissions reflect on race and attainment (Moody, 2017). Kingston University (2016: n.p.) has made progress in removing the minority ethnic attainment gap, as noted in their TEF submission:

Since $2011 / 12$ when the gap stood at $28.5 \%$, over the last 3 years the gap has continued to close from $19.7 \%$ in 2013/14 (English sector 16.0\%), to $16.1 \%$ in 2014/15 (English sector 16.0\%) and 15.4\% in 2015/16 mirroring the English sector average.

However, there is still more work to do. The disciplines (such as dance, drama, music and sociology) involved in Taking Race Live (TRL) face some of the above challenges, including Eurocentric and androcentric curricula, lack of ethnic diversity among staff and uneven attainment and retention. To advocate for diversity within assessment and learning, Jessie McCabe, a school student in England, took to Twitter to bemoan the lack of women in the Edexcel's A level music curriculum. This led to a debate that engaged subject associations and exam boards, leading to some inclusion of women within higher education curricula and assessment (Khomami, 2015). According to Higher Education Statistics Agency (HESA) data collected in the academic year 2010/11, minority ethnic students taking a degree in a single identifiable discipline were notably underrepresented in music, dance and drama, making up only 8 per cent (Woodfield, 2014: 27). Such findings can be related to a lack of retention that is caused by a number of issues (financial, caring responsibilities, mental health and so on). Against a sector rate of 22 per cent, students in music, dance and drama had a high rate of leaving without an award due to 'other personal' reasons (32 per cent). Against a sector rate of 4 per cent of students leaving due to 'exclusion', some disciplines showed rates twice as high or more, with sociology at 8 per cent (ibid.: 54-5).

Given these contextual factors, the TRL project was formed at Kingston University in London. This was a four-year co-curricular initiative that brought together the disciplines of sociology, dance, drama, music, film, media and television, and students from a range of ethnic backgrounds, to actively engage with their experiences, and to enliven understandings of race and ethnicity in and outside of the classroom.

\section{The Taking Race Live project}

The TRL project was established to complement relevant modules within students' second year. It was conducted during this year of study because it could build on 
their learning from the first year and there were not the pressures of third-year end-of-degree assignments preventing participation. The project was not compulsory for students, and those who joined remained involved for the year. Only one student left the project, because of family illness. The majority of students were in their early 20s, and participants were from a range of ethnic backgrounds (see Table 1). In 2014/15, sociology worked with drama; in 2015/16, with music; in 2016/17 and 2017/18 with dance, music and television. The project took place over two 12-week semesters.

Table 1: Ethnic background of students and staff participating in Taking Race Live

\begin{tabular}{lcccccccc}
\hline & \multicolumn{2}{c}{$2014 / 15$} & \multicolumn{2}{c}{$2015 / 16$} & \multicolumn{2}{c}{ 2016/17 } & \multicolumn{2}{c}{ 2017/18 } \\
& Students & Staff & Students & Staff & Students & Staff & Students & Staff \\
\hline Black & 2 & - & 3 & - & 1 & - & 2 & - \\
Asian & - & - & 2 & - & 1 & - & - & - \\
Mixed race & 1 & 1 & - & 1 & 2 & 1 & 1 & 1 \\
White & 5 & 2 & 1 & 1 & 3 & 2 & 2 & 2 \\
Mixed European & - & - & - & - & 1 & 2 & 1 & 1 \\
\hline
\end{tabular}

In Semester 1, the project was introduced to students on participating modules; staff took turns at co-teaching on modules to provide students with theoretical perspectives from each discipline. This benefited students by broadening the content of the modules, and it benefited the staff by enabling participation in cross-disciplinary expertise. Two staff-led field trips took place in Semester 1 each year. These included trips to the National Portrait Gallery, the Black Cultural Archives, the play A Man of Good Hope at the Young Vic and Tate Britain's 'Artist and Empire' exhibition. For some students, these field trips were their first experience of a public exhibition or performance, and opened up possibilities for future independent use of such public resources. During the exhibition field trip, students attended a lecture by an in-house expert or curator focusing on race; they were then organized into cross-disciplinary groups and undertook activities and discussion as they toured the exhibition. As well as engaging with expert scholars, students and staff listened to one another's stories and related the artefacts and narratives of the exhibitions to their own racial and ethnic experiences. Staff and students got to know one another more closely than might otherwise be the case, opening conversations about race into a critical studentengaged learning process.

While not the focus of this article, TRL also included an element of employability. In Semester 1, students on participating modules were invited to apply to become members of the organizing committee and worked with module staff as student partners for the rest of the project (see Table 2). Between 6 and 12 student posts were advertised (up to 4 for each discipline). Students submitted a formal application and $\mathrm{CV}$ in response to a job description, and underwent shortlisting and an interview. Those who were offered a place on the committee were given an honorarium (provided by the Office for Fair Access Agreement Fund). Students gained skills such as event organization, team and committee working, communication, peer evaluation and time management. 
Table 2: Profile of participating student partners by subject

\begin{tabular}{lcccc}
\hline & $2014 / 15$ & $2015 / 16$ & $2016 / 17$ & $2017 / 18$ \\
Student partners & 8 & 6 & 8 & 6 \\
\hline Drama & 4 & - & - & - \\
Sociology & 4 & 3 & 4 & 2 \\
Music & - & 3 & 1 & 2 \\
Media and TV & - & - & 2 & 1 \\
Dance & - & - & 1 & 1 \\
\hline
\end{tabular}

In Semester 2, the organizing committee were responsible for determining and delivering project events. These included pop-up events, a festival and participation in Kingston Connections (a week-long festival organized by the university, Kingston Borough Council and other institutions). They also organized the end-of-year symposium, meeting weekly to lead the creative practices and performances that would be included in this and the pop-up events. All of these events took race and ethnicity as a central theme. They showcased student work alongside internationally renowned keynote speakers and performers representing the disciplines. The symposium was open to an audience from across the university and to members of the public.

\section{Critical focus and methodology}

The aim of the project was to provide an informal and inclusive context for students to share their personal experiences of race and ethnicity, and to subsequently engage the wider academic community in the conversation. We were guided by the concept of 'liveness', as expounded by Les Back and Nirmal Puwar (2012) in their edited book Live Methods. Here, they argue for the potential of developing and employing inventive ways of 'doing sociology', to make research responsive to social life - to bring it alive. Their concept of 'live sociology' implies giving attention 'to how a wider range of senses changes the quality of data and makes other kinds of critical imagination possible' (Back and Puwar, 2012: 29). Building on this idea, TRL, fundamentally a sociological project, brought on board students and staff from media and performing arts (dance, music and drama), in order to expand the scope of the enquiry. The rationale behind this interdisciplinary approach was two-fold. First, we were motivated by the idea that experiences of race are first and foremost embodied. Therefore, the expressive modalities of dance, music and drama were apt to facilitate an alternative take on sociological concerns. Similarly, the involvement of students from media and television recognized the role of digital and screen environments in shaping embodied experiences of race. Bringing students from different disciplines to work together allowed us to challenge discipline-informed ways of thinking about race, engaged a wider range of senses and made possible other kinds of critical imagination. Second, we were also interested in how these different expressive modalities could be used to bring the process and the sociological issues we tackled to a wider public, in particular during the final symposium, in order to bring 'sociology alive'.

Back and Puwar's (2012) concept of 'live methods' sits within recent discussions on the importance of making sociology public. According to Buraway (2005), public sociology is committed to engaging different publics in multiple contexts, in order to 
address key sociological issues. He distinguishes between 'traditional' and 'organic' public sociology, where the former is concerned with taking sociological knowledge outside academia, while the latter is concerned with creating sociological knowledge by engaging the wider public. The latter implies a more radical shift in the understanding of academic authorship. In addition, Buraway (ibid.) argues that students on undergraduate programmes are perhaps one of the key publics with which sociology needs to engage. He proposes to involve students in the production of sociological knowledge by making sociology relevant to their lives. TRL responds to this appeal by developing a more egalitarian dialogue between students and staff, and by bringing students' lived experiences to the forefront of sociological discussion. It also goes beyond traditional ways of producing sociological knowledge by stepping outside its disciplinary boundaries and focusing on the collaborative creation of material, in the form of movement, sound, image and creative text. Students participating in TRL had ownership over the material produced and were active decision makers throughout the process.

In order to capture students' experiences of this process, we engaged in ongoing end-of-year evaluations through focus groups, semi-structured individual interviews and a survey with open-ended questions (see Table 3). The utilization of interviews and focus groups was a way to 'facilitate access to "tacit, uncodified and experiential knowledge", as well as to the opinions and meanings of the participants' (Johnson, 1996: 521-3, cited in Hopkins, 2007: 528-9). Each focus group lasted for between an hour and 90 minutes, and interviews were up to an hour long. The number of students in the focus groups varied each year, with between four and eight participants at a time. The focus groups and interviews were comprised of project committee members. Ethical approval was granted, and participant consent obtained, including for photographs. We asked participants questions about their engagement and involvement in TRL, what they learned about themselves, race and ethnicity, the challenges they encountered, how it affected their learning on their course and how it might impact on their future endeavours. While the methods of collecting student voices differed slightly year to year depending on available resources, the questions asked were similar across all three research tools, allowing for a more overarching analysis of responses.

Table 3: Different research tools used to capture student experience

\begin{tabular}{lcccc}
\hline & $2014 / 15$ & $2015 / 16$ & $2016 / 17$ & $2017 / 18$ \\
\hline Questionnaire & 17 & - & - & - \\
Interviews & - & 1 & 5 & 1 \\
Focus groups & 1 & 2 & - & 1 \\
\hline
\end{tabular}

Regular evaluations ensured that TRL drew upon aspects that were meaningful to young people and gave students a voice in our future planning (Holt, 2006). The project evolved year-on-year in response to student feedback and staff observations. A key development was the deepening of interdisciplinary working and an embodied approach during the weekly sessions. This involved the gradual substitution of discussion-based meetings by performative explorations of experiences of race and ethnicity (for example, through music, dance, film, script writing and images). This performative process drew on techniques of applied drama. Prendergast and Saxton (2013) explain that applied drama is a wide field of dramatic arts practices 
that are process-based and aim to benefit participants, rather than the audience, normally addressing issues that concern the community involved. A recent example of applied drama can be found in the work of Sutherland (2013) in South Africa. She employed this approach with young people in higher education to address social structures of power and identity, and used the body as a key site of learning. This complements the work of Bagley and Castro-Salazar (2012) among undocumented Mexican students in America. We used these case studies to inform the process of our work with students.

\section{Reflections on the data}

In our thematic analysis of interview and focus-group data we identified three overlapping themes that students recognized as positive learning experiences: (1) breaking taboos around talking about race; (2) developing interdisciplinary learning and deepening the intersection between embodied and theoretical knowledges of race; and (3) exploring race in relation to the self and others.

\section{Breaking taboos around talking about race: Making a space 'for all' to fit in}

TRL broke taboos around talking about race, first by creating informal spaces in which students could talk about these issues, and second by emphasizing that all identities are shaped by race, including those of White students. Many students felt that, even though issues around 'race' were discussed in seminars and lectures, classroom discussions were often stunted by a general uneasiness when talking about race. One drama student put it: 'I think race and ethnicity is a silent but heavy topic' (drama, 2014/15). For many, race could be an uncomfortable and 'touchy' subject that was difficult to talk about, particularly between people of different races, and students were often afraid of 'saying the wrong thing' or 'seeming racist'. Both students of colour and White students participated in TRL, and each had different experiences of their university curriculum. While White students often felt that they did not have racialized experiences and felt unable to comment on issues around race, ethnic minority students could feel uncomfortable that their ethnicity was being highlighted and that the onus was put on them to offer insights: 'in class when Black issues are raised, it feels like everyone turns and looks at the Black student to comment and then moves on' (drama, 2014/15).

By contrast, students felt TRL created a space where they were able to talk about their experiences of race and their differences. It constituted 'an opportunity ... to let it be like an outspoken thing where ... you can tell people about it and you can get people to understand race better' (sociology, 2015/16), and it 'addressed the idea of race head on' (drama, 2014/15). TRL was able to create informal spaces, outside of the participants' usual classroom setting, which allowed for more personal, direct and ongoing conversations between participants. The more informal atmosphere created by extra-curricular activities - meetings, workshops, field trips, interim festivals and the symposium - meant that participants felt less bound by more formalized classroom interactions, more comfortable and able to talk more freely. 'I do think that it was really, really nice to be able to sit down with people and talk about race and ethnicity and culture. ... and people's experiences' (music, 2015/16). Another student said, 'Normally I don't talk about my feelings. Who cares about it? It was nice to open up' (sociology, 2017/18). 
The second contributing factor was that TRL aimed to foreground more specifically the ways all identities are shaped by conceptions and embodied experiences of race and ethnicity. As Crozier et al. (2016: 49) observe, universities are both 'physical and cultural spaces and are often spaces where there is a struggle for the "dominant culture" to endure - one that is mainly White middle-class, where minority ethnic students are marginalised and excluded'. Such broader social contexts shape classroom discussions and contribute to ethnic minority students' reluctance to emotionally engage and speak out in those spaces. Although very keen on the project in the abstract, for example, a Black female drama student was reluctant to promote it in class, explaining 'it is hard for me to make my race an issue' (drama, 2014/15). As one of only a few Black students in her class, she had put a lot of work into 'fitting in' by making her race invisible, and it took a lot of courage for her to present herself as 'different'. Comments such as these acknowledge the fact that while 'Whiteness' is structurally produced as invisible (Frankenberg, 1993; Dyer, 2002), ethnic minority students have to work hard to achieve the same degree of racial invisibility. John Warren (2001: 92), during his research on the performativity of Whiteness in classroom spaces, observed, 'Whiteness, while a systemic historical process that is diffuse and abstract, is also located through embodiment - through a repetition of mundane and extraordinary acts that continually make and remake Whiteness, all while eluding scrutiny and detection.' In a similar manner, students noted that outside of TRL, the intellectual space accorded to discussions of race was circumscribed and seen as relevant only to Black students (see also Puwar's (2004) concept of 'space invaders').

TRL aimed to disrupt these practices by making spaces for everyone to think about race and identity. Both students of colour and White students went through their own process of learning about others' experiences of race and their own. A White female student said, 'I think it just generally helped me to consider and think about race and ethnicity on a continual basis' (sociology, 2014/15). A White male student concurred, '[TRL] greatly improved [my] understanding of race and especially my own race' (sociology, 2014/15). What united their experiences was an understanding of how they themselves and everyone is shaped through embodied racialized practices. One Black female student commented that on TRL her experiences of race and herself took on new meaning and acceptance as 'it's made me feel like I can fit in and it's not fitting in with just other Black students, it's fitting in with everyone' (drama, 2014/15).

While TRL opened up informal spaces where students could feel united, discussions were not without discomfort and conflict. A student reflecting on her own behaviour observed: 'I didn't start very professionally - I often said things that upset the group, 'cause I had an issue with one of the students' (music, 2017/18). Students felt that the conflicts they worked through were productive learning experiences. According to one student, reflecting on the disagreements the group had during the project, 'If you say something and someone else feels differently, it doesn't mean you're wrong. We feel differently and there is definitely something I can learn from you' (sociology, 2017/18). The project acknowledged that debates around race went to the very core of everyone's identity. As such, TRL provided, as much as possible, an inclusive setting in which students got to know each other, and in which boundaries and identities could be explored and brought alive without reference to formalized learning outcomes. 


\section{Developing interdisciplinary learning and deepening the intersection between embodied and theoretical knowledges around race}

Apart from a sense of informality and inclusivity, many students across the life of the project felt that TRL offered interdisciplinary out-of-classroom learning opportunities for them to explore different ways of thinking about race. The configuration of disciplines involved in TRL changed each year, but what was stable was the collaboration of sociology with performative arts and media studies. Against this background, sociology students appreciated learning about race as embodied, while arts students appreciated the theoretical and historical contexts of race that led them to explore their personal experiences through the medium of performance. For instance, 'My favourite part was working with sociology students ... It was really nice bringing their research to life' (drama, 2014/15). Another student said, 'When we did our dance, we tried to express intentions [found in] sociology - how individuals are welcomed into a society and how some aren't' (dance, 2017/18). Although students found the process rewarding, they also commented that more could be done to integrate the disciplines. According to one student, 'It was quite hard because I felt the only way I could bring dance into it was to just dance. But there's so much more to dance than just that' (dance, 2016/17). In fact, in the first three years of TRL, performing these experiences - articulating them in movement, sounds and words, and reflecting critically on them through sociological theories - had been confined to pop-up events, the final symposium and rehearsals. However, in response to students' comments and staff observations, in the last iteration of TRL (2017/18), there was a decisive shift towards a more embodied and participative approach in the running of the project.

Performative practices became an integral part of weekly activities, with discussion-based meetings replaced with lab sessions. In these sessions, staff encouraged embodied and participative engagement, implying the use of the living body as a tool for generating and sharing experiences. This foregrounded 'the embodied and located nature of racial practices', which are part of everyday spaces and routines (Sutherland, 2013: 734). Race is inscribed and lived through the breathing and moving body, and performative forms of knowledge such as dance, music and acting enabled effective ways of accessing one's own, and understanding others', experiences. We took inspiration from McCarthy-Brown's (2017) proposal for the development of a dance pedagogy that acknowledges and nurtures the diversity of our students, and from the tenets of applied drama (Prendergast and Saxton, 2013). Students worked individually or in pairs, often alongside a member of staff, to plan and facilitate the labs using methods and tools of their own specific disciplines. In each lab, the students in charge brought materials to discuss, such as videos, pictures or texts, or proposed exercises and tasks to carry out together. Working closely across disciplines was challenging, but enhanced learning and, participants agreed, led to 'deeper', more nuanced understandings of race. One student explained:

It was difficult because you work with new people from different disciplines, but in the end, this worked out nice. We imagined we would just do sociology, and dance students would just do the dancing. But we ended up working in other disciplines, and that was hard and very slow sometimes, but I ended up knowing more about myself and about my team. (Sociology, 2017/18) 
Both the process and the content produced in weekly creative tasks became part of the performances presented in the final symposium. Weekly labs involved sharing of experiences, and personal reflections, with reference to sociological and critical race theories. Students integrated notions gained through curricular activities with the informal and lived context of this project, making links between personal lives and academic knowledge.

\section{Deciphering the self: Communicating experience and learning from others}

For our students, TRL was not only about the ability to think through 'race' from different perspectives, but also about the exploration and communication of their own experiences of race and identity. Significantly, the bulk of student responses dwelt on the fact that TRL activities allowed them to connect abstract academic debates to their own and their peers' experiences. One student observed, 'That's why I took it [TRL] because it was about me' (music, 2017/18). Similarly, a sociology student said, 'It gave me a chance to understand where I'm from better' (sociology, 2015/16).

Race and ethnicity are addressed in course curricula to varying degrees, but their actual, everyday experience are not as 'present'. This can make it difficult for students to engage on an emotional or imaginative level with what is being taught. Within academia, there is often a mind/body split, by which students are taught the cognitive rigours of how to think, observe and express that thinking through various discursive forms, especially within sociology. Back (2007: 164) has argued that academics should 'document and understand social life without assassinating it', but that 'the lacklustre prose of methodological textbooks often turns the life of the research encounter into a corpse fit only for autopsy' (ibid.: 163). Too often, academic contributions remain between student(s) and lecturer(s) and assessed coursework and research projects in a Turnitin box. A Black female sociology student spoke to this effect, stating:

There's such a difference between being taught and reading something, to then understanding it and applying it to different situations ... Often individuals' work, even when it is outstanding, is not shared outside of their lecturer marking and grading it ... The collaboration brought the students' work and experiences to life. (Sociology, 2014/15)

By allowing students to step outside the academic and discipline-specific confines of the classroom, TRL enabled them to engage with the subject on an emotional and experiential level. A dance student's reflections on her friends' engagement with TRL captured this:

B.'s from Berlin but she's also part-Ghanaian, and P. is from Greece ... and I think they engaged more with it and they had their own cultures to put into the formula.... When they were talking about different cultures and how they've been perceived in certain places; they were able to connect with that and think, 'Actually yeah, I've had that experience, so yeah that makes a point.' (Dance, 2016/17)

Students related the deeper sense of learning to what they had learnt about themselves and others. Learning on TRL was not disembodied or abstract but put them at the heart of the curriculum. 
Going beyond the confines of the classroom was not just about exploring their own experiences, but also about sharing experiences and listening to others. Students' contributions took on more than traditional academic forms, as noted by Back (2007), where experiences of race can remain invisible. As one student put it, 'In this project we told part of our life to everyone, even if it was a small part' (sociology, 2017/18). Another observed, 'It was really eye-opening, the journey that people go through and hearing about people's personal experiences' (sociology, 2016/17).

Sharing and communicating experiences around race and identity allowed students to attach significance to those experiences, rather than shutting them off, as they often do in the context of academic debate:

But here the experiences that we had as women or as Black women, I experienced them somehow - but I never express it or talk about it. But suddenly you notice, 'Ooh other people had the same experience as me. Alright! I'm not the only one' - I felt more secure about myself, about what I look like or who I am in general. (Sociology, 2017/18)

The interdisciplinary character of the labs further facilitated this process of communicating experiences about the self, allowing students to experiment with different forms of embodied and discursive media. By using both discursive and nondiscursive forms of understanding and communicating, we created a common platform in which both sociology and arts students could participate. A student observed: 'I'm all about talking, talking and talking, but there are other types of communication than just opening your mouth' (sociology, 2017/18). Another added:

as a music student, it's not always easy to articulate myself to someone who is a sociology student. ... I started out really shy, because I didn't know how to talk to any of them, but I started to open up towards the end. ... It was easier when we did activities together - if we hadn't done those exercises, I would still be in the corner not talking to anyone. (Music, 2017/18)

Exploring race in relation to their own experiences, and sharing those experiences with others, conjured forms of recognition from fellow students, and took discussions of race from a confined, formalized and mostly private space to an open, active, live and eventually public space at the end-of-year symposium.

\section{Conclusion}

TRL created a space for students to share their experiences of race. Framing our project and data analysis with the concepts of 'liveness' and 'public sociology' has assisted in making visible lived realities of race and racialization. In particular, the informal and interdisciplinary nature of the project allowed students to break taboos when talking about race with their peers and tutors, and to develop a more embodied understanding of racial experiences, and therefore to acquire a better understanding of themselves and others.

Nevertheless, while the process had an overall positive impact on the students involved, as demonstrated by the qualitative data discussed above, the project also included moments of discomfort and even conflict. These moments, which students eventually recognized as a key part of the learning process facilitated by $T R L$, were caused by the challenge posed by working across disciplines, and therefore by the need for students to step out of their comfort zone. Students critically considered any uneasiness experienced during the process, by engaging in self-reflection and group 
discussion. The TRL collaboration helped to bring alive " education-as-process" and "education-as-experience"' (Salama, 2014: 88). In addition, for most of the students involved in the committee, TRL was the first experience of working semi-professionally in the production of events and performances.

Overall, TRL evidenced the importance of generating an informal space where students could develop their own voices and share experiences of race. In questioning traditional structures and bringing students' agency at the forefront, it is suggested that such an informal space can enable more impactful and meaningful changes in higher education with respect to race awareness. TRL also demonstrated the potential of interdisciplinary learning in exploring and sharing experiences that are collective as much as personal. In this sense, a project such as this can be successfully applied to tackle a variety of issues concerning students' identities and experiences in higher education and beyond. Finally, TRL acknowledges the fact that attainment in higher education has an emotional and lived component that cannot be easily measured through metrics but needs to take into account students' self-perceptions and sense of personal accomplishment. Further research, such as a longitudinal study that includes a quantitative analysis of students' progression over time, is required to better understand the impact of projects such as TRL on students' learning and achievement.

\section{Acknowledgements}

We are incredibly grateful to all of the students who took part in the TRL project, and to all of the staff who worked on and supported this endeavour, along with the scholars, artists and organizations who were a continued source of inspiration.

\section{Notes on the contributors}

Sonya Sharma is Senior Lecturer in Sociology at Kingston University, UK. Her research focuses on the social relations of prayer in healthcare settings, and currently on the ways in which women healthcare chaplains contribute to living well together. She is coeditor of Women and Religion in the West: Challenging secularization (Ashgate, 2008) and Religion, Equalities and Inequalities (Routledge, 2016).

Elena Catalano is Senior Lecturer in Dance at Kingston University, UK, and a freelance dance artist. Her current research focuses on spirituality, dance, somatics and ecophenomenology. As a dancer, she regularly works within a variety of settings to empower disadvantaged communities, and she is a core member of the ReRooted Dance Collective. Her choreographic work explores issues around mental health, women, nature and the city.

Heidi Seetzen is a freelance social researcher and a sculptor at Thames-Side Studios, London. She was previously Senior Lecturer in Sociology at Kingston University, UK. Her research focuses on urban communities and cultural and creative practices. Recent publications include 'Citizen-led micro-regenerations: Case studies of civic crowdfunding' in The Production of Alternative Urban Spaces, edited by Jens Kaae Fisker, Letizia Chiappini, Lee Pugalis and Antonella Bruzzese (Routledge, 2019).

Helen Julia Minors is Associate Professor of Music at Kingston University, UK, where she is Course Leader and MA Music Admissions Tutor. She is a musicologist and performer working on twentieth- and twenty-first-century music, music and gender and music and dance. Publications include Music, Text and Translation (Bloomsbury, 2013) and Paul Dukas: Legacies of a French musician (Routledge, 2019). 
Sylvia Collins-Mayo is Associate Professor in the Sociology of Religion at Kingston University, UK. She has researched how young people engage with the Christian heritage of Britain, and has written on how religious beliefs and practices are lived out in everyday life. She is co-editor of Religion and Youth (Ashgate, 2010) and co-author of The Faith of Generation Y (Church House, 2010).

\section{References}

Alexander, C. and Arday, J. (2015) 'Introduction: Race and higher education'. In Alexander, C. and Arday, J. (eds) Aiming Higher: Race, inequality and diversity in the academy. London: Runnymede, 4-5.

Back, L. (2007) The Art of Listening. Oxford: Berg.

Back, L. and Puwar, N. (eds) (2012) Live Methods. Malden, MA: Wiley-Blackwell.

Bagley, C. and Castro-Salazar, R. (2012) 'Critical arts-based research in education: Performing undocumented historias'. British Educational Research Journal, 38 (2), 239-60.

Bhopal, K. (2018) White Privilege: The myth of a post-racial society. Bristol: Policy Press.

Burawoy, M. (2005) 'For public sociology'. American Sociological Review, 70 (1), 4-28.

Crenshaw, K. (1989) 'Demarginalizing the intersection of race and sex: A black feminist critique of antidiscrimination doctrine, feminist theory and antiracist politics'. University of Chicago Legal Forum, 1, 139-67.

Crozier, G., Burke, P.J. and Archer, L. (2016) 'Peer relations in higher education: Raced, classed and gendered constructions and othering'. Whiteness and Education, 1 (1), 39-53.

Dyer, R. (2002) 'The matter of whiteness'. In Rothenberg, P.S. (ed.) White Privilege: Essential readings on the other side of racism. New York: Worth Publishers, 9-14.

ECU (Equality Challenge Unit) (2016) 'Equality in higher education: Statistical report 2016'. Online. https://tinyurl.com/yxvkvv5r (accessed 4 April 2019).

Frankenberg, R. (1993) White Women, Race Matters: The social construction of whiteness. Minneapolis: University of Minnesota Press.

Holt, L. (2006) 'Exploring "other" childhoods through quantitative secondary analyses of large scale surveys: Opportunities and challenges for children's geographers'. Children's Geographies, 4 (2), 143-55.

Hopkins, P.E. (2007) 'Thinking critically and creatively about focus groups'. Area, 39 (4), 528-35.

Hussain, M. (2015) 'Why is my curriculum white?'. NUS News, 11 March. Online. https://tinyurl.com/ y475hth2 (accessed 4 April 2019).

Khomami, N. (2015) 'A-level music to include female composers after student's campaign'. Guardian, 16 December. Online. http://tinyurl.com/y26w3utb (accessed 3 April 2019).

Kingston University (2016) TEF Year Two Provider Submission. London: Kingston University. Online. https://tinyurl.com/y3o8rulx (accessed 4 April 2019).

McCarthy-Brown, N. (2017) Dance Pedagogy for a Diverse World: Culturally relevant teaching in theory, research and practice. Jefferson, NC: McFarland and Company.

McDuff, N., Tatam, J., Beacock, O. and Ross, F. (2018) 'Closing the attainment gap for students from black and minority ethnic backgrounds through institutional change'. Widening Participation and Lifelong Learning, 20 (1), 79-101.

Moody, J. (2017) 'TEF results - A missed opportunity for progress on equality'. Wonkhe, 25 June. Online. http://tinyurl.com/y46544ga (accessed 3 April 2019).

Morgan, W. (2016) 'Why is my professor still not black?'. Times Higher Education, 14 March. Online. http://tinyurl.com/y4gwb3tz (accessed 3 April 2019).

Prendergast, M. and Saxton, J. (2013) Applied Drama: A facilitator's handbook for working in community. Bristol: Intellect.

Puwar, N. (2004) Space Invaders: Race, gender and bodies out of place. Oxford: Berg.

Richardson, J.T.E. (2018) 'Understanding the under-attainment of ethnic minority students in UK higher education: The known knowns and the known unknowns'. In Arday, J. and Mirza, H.S. (eds) Dismantling Race in Higher Education: Racism, whiteness and decolonising the academy. Cham: Palgrave Macmillan, 87-102.

Ross, F.M., Tatam, J.C., Livingstone Hughes, A., Beacock, O.P. and McDuff, N. (2018) '"The great unspoken shame of UK higher education": Addressing inequalities of attainment'. African Journal of Business Ethics, 12 (1), 104-15. 
Salama, A.M. (2014) '"Liveness" beyond design studio pedagogy: Layers of "live" within and across the boundaries of classroom settings'. In Proceedings of the 2nd Annual AAE Conference: Living and Learning, University of Sheffield, 3-5 September 2014. Sheffield: Association of Architectural Educators, 88-93.

Sutherland, A. (2013) 'The role of theatre and embodied knowledge in addressing race in South African higher education'. Studies in Higher Education, 38 (5), 728-40.

Warren, J.T. (2001) 'Doing whiteness: On the performative dimensions of race in the classroom'. Communication Education, 50 (2), 91-108.

Woodfield, R. (2014) Undergraduate Retention and Attainment across the Disciplines. York: Higher Education Academy. 